\title{
KARAKTERISTIK PUKAT CINCIN MINI DI PEMALANG, JAWA TENGAH
}

\author{
Erfind Nurdin ${ }^{*}$ dan Hufiadi ${ }^{*}$ \\ Peneliti pada Balai Riset Perikanan Laut-Muara Baru-Jakarta
}

\begin{abstract}
ABSTRAK
Penelitian mengenai karakteristik pukat cincin mini di Pemalang, Jawa Tengah merupakan bagain dari hasil penelitian cahaya pada tahun 2004 di Pemalang, Jawa Tengah, dengan cara mengikuti kapal mini purse seine komersil yang menggunakan alat bantu cahaya. Pengukuran dimensi alat tangkap dan biologi ikan dominan hasil tangkapan dilakukan di atas kapal. Informasi yang dihasilkan antara lain total hasil tangkapan mini purse seine dari 27 kali tawur di perairan Pemalang $(3393,5 \mathrm{~kg})$ didominasi oleh jenis ikan tembang (Sardinella fimbriata) yaitu $60,7 \%$ dari total hasil tangkapan, diikuti oleh layur $(11,3 \%)$, cumi-cumi $(8,8 \%)$, tongkol $(6,7 \%)$, dan ikan lain kurang dari $5 \%$. Laju tangkap mini purse seine yang diperoleh $125,7 \mathrm{~kg}$ per tawur. Karakteristik mini purse seine di Pemalang efektif untuk penangkapan ikan.
\end{abstract}

KATA KUNCl: purse seine mini, penangkapan, perairan pantai Jawa Tengah

\section{PENDAHULUAN}

Pukat cincin (purse seine) merupakan alat tangkap aktif yang sangat potensial untuk menangkap ikan-ikan pelagis kecil dan pelagis besar dalam kawanan yang besar, yang berada di lapisan permukaan laut (Sainsbury, 1975). Pukat cincin merupakan jaring rata (flat net) yang panjang terdiri dari bagian-bagian kantong (bunt), badan (body), dan sayap (wing). Cara pengoperasian pukat cincin dilakukan dengan melingkarkan atau mengurung kawanan ikan, kemudian bagian bawah jaring ditutup dengan menarik tali kolor (purse line), sehingga kawanan ikan yang terkurung bebas tidak dapat meloloskan diri secara mendatar dan vertikal. Kantong terletak di bagian tengah badan atau di pinggir bagian sayap, merupakan bagian yang sangat penting oleh karena bagian ini akan menampung hasil tangkapan sebelum diangkat ke atas kapal.

Alat tangkap yang dominan digunakan dalam perikanan pelagis kecil di Laut Jawa adalah pukat cincin. Perkembangan armada pukat cincin membawa dampak terhadap keseluruhan bentuk perikanan pukat cincin. Perbedaan kepemilikan modal, perhitungan ekonomis dan teknis serta kondisi basis penangkapan merupakan sebagian penyebab munculnya 3 bentuk perikanan pukat cincin yang berkembangan saat ini. Armada pukat cincin berkembang pesat sejak pelarangan operasi trawl pada tahun 1980 dan mencapai puncak pada tahun 1985 dengan jumlah 520 unit. Ukuran kapal maupun alat tangkap terus bertambah besar dari tahun ke tahun, sehingga dapat menjangkau daerah penangkapan yang semakin jauh (Wijopriono et al., 1995). Hasil penelitian menunjukkan bahwa hasil tangkapan per kapal dan rata-rata ukuran ikan yang tertangkap cenderung semakin kecil. (Potier \& Sadhotomo, 1995; Nurhakim et al., 1995; Merta \& Eidman, 1995).

Berdasarkan pada sumber daya ikan yang menjadi target pengoperasian, bentuk geografi fisik (sungai, pantai), dan geografi manusia (permodalan, tempat pendaratan, dan potensi pasar), maka bentuk perikanan pukat cincin dapat dibedakan menjadi 3 jenis yaitu pukat cincin mini, sedang dan besar (Potier \& Sadhotomo, 1995). Perikanan pukat cincin mini dicirikan antara lain kapal menggunakan material kayu dengan panjang antara 10 sampai dengan $18 \mathrm{~m}$, dengan kapasitas 1 sampai dengan 2 ton. Tenaga penggerak menggunakan mesin luar (outboard) terdiri atas 1 sampai dengan 2 buah dengan kekuatan 25 sampai dengan $40 \mathrm{PK}$. Jaring yang digunakan berukuran antara 200 sampai dengan $300 \mathrm{~m}$ dan dalam 40 sampai dengan $60 \mathrm{~m}$ serta ukuran mata jaring di bagian kantong 0,75 inci. Daerah penangkapan relatif tidak jauh dari pantai dan jumlah hari dalam 1 trip antara 1 sampai dengan 5 hari.

Dalam taktik penangkapan (fishing tactics), kapal-kapal pukat cincin menggunakan alat bantu pengumpul ikan yaitu cahaya artifisial. Besar kelompok ikan yang dapat dikumpulkan (fish aggregation) sangat tergantung kepada besar intensitas cahaya yang digunakan. Kajian 
terhadap hasil tangkapan (catch) ikan pada pukat cincin di Laut Jawa menunjukkan perbedaan yang signifikan antara pukat cincin yang menggunakan sumber cahaya petromak dan lampu fluorescent yang mempunyai intensitas yang lebih tinggi (Wijopriono, 1993). Saat ini kompetisi di antara kapal-kapal pukat cincin dalam penggunaan cahaya artifisial semakin tinggi dan cenderung tidak terkendali. Nelayan beranggapan bahwa semakin tinggi intensitas cahaya yang digunakan, semakin besar kelompok ikan yang dapat dikumpulkan. Sehingga dalam perkembangan terakhir ini beberapa kapal pukat cincin sudah menggunakan lampu fluroescent dengan kekuatan $30 \mathrm{Kw}$. (Sadhotomo et al., 1995).

Data mengenai alat tangkap dan operasional diperoleh melalui pengukuran dan pengamatan langsung saat operasi penangkapan di laut. Data biologi hasil tangkapan diperoleh dengan cara pengukuran langsung di atas kapal saat operasi penangkapan dan hasil yang didaratkan oleh kapal penangkap di tempat pendaratan ikan yang meliputi morfometrik ukuran (panjang) jenis ikan dominan.

Perhitungan beberapa parameter alat tangkap menggunakan formula yang dikemukakan oleh Prado \& Dremiere (1991), yaitu:

Bobot jaring bersimpul:

$W=H x L x R t e x / 1000 \times K$

di mana:

$\mathrm{W}$ = Bobot jaring di udara yang diperkirakan ( $\mathrm{g}$ )

$\mathrm{H} \quad=$ Jumlah baris simpul pada tinggi jaring

$\mathrm{L} \quad=$ Panjang jaring dalam keadaan tegang

Rtex $=$ Ukuran benang jaring

$\mathrm{K}=$ Faktor korelasi simpul
Daya apung dan tenggelam:

$P=A \times(1-D W / D M)$

di mana:

$\mathrm{P}=$ Bobot di dalam air $(\mathrm{Kg})$

$A=$ Bobot di udara $(\mathrm{Kg})$

$D W=$ Densitas air $(\mathrm{g} / \mathrm{cc})$; untuk air laut 1,026

$\mathrm{DM}=$ Densitas bahan $(\mathrm{g} / \mathrm{cc})$

Hangging ratio:

$E=L / L O$

di mana:

$$
\begin{aligned}
E= & \text { Hangging ratio (\%) } \\
\mathrm{L}= & \text { Panjang tali tempat lembaran jaring }(\mathrm{m}) \\
\mathrm{LO}= & \text { Panjang jaring tegang yang digantung } \\
& \text { pada tali tersebut }
\end{aligned}
$$

\section{Daerah Penangkapan}

Pengamatan tentang pengoperasian dan komposisi hasil tangkapan purse seine dilakukan pada bulan September dan Oktober 2004 pada kapal nelayan yang berbasis di Pemalang. Daerah penangkapan ikan terdapat di perairan sebelah utara Jawa Tengah pada posisi geografis sekitar $06^{\circ} 44^{\prime} 005 \mathrm{~S}-109^{\circ} 19^{\prime} 285 \mathrm{E}$, dengan jarak 10 sampai dengan 30 mil dari pantai yang ditempuh dengan waktu antara 3 sampai dengan 4 jam (Gambar 1.).

\section{Deskripsi Kapal}

Secara umum, nelayan purse seine di Pemalang menggunakan 2 jenis kapal penangkap ikan yaitu kapal jaring sebagai penangkap dan kapal lampu sebagai kapal bantu terdiri atas 3 sampai dengan 4 kapal.

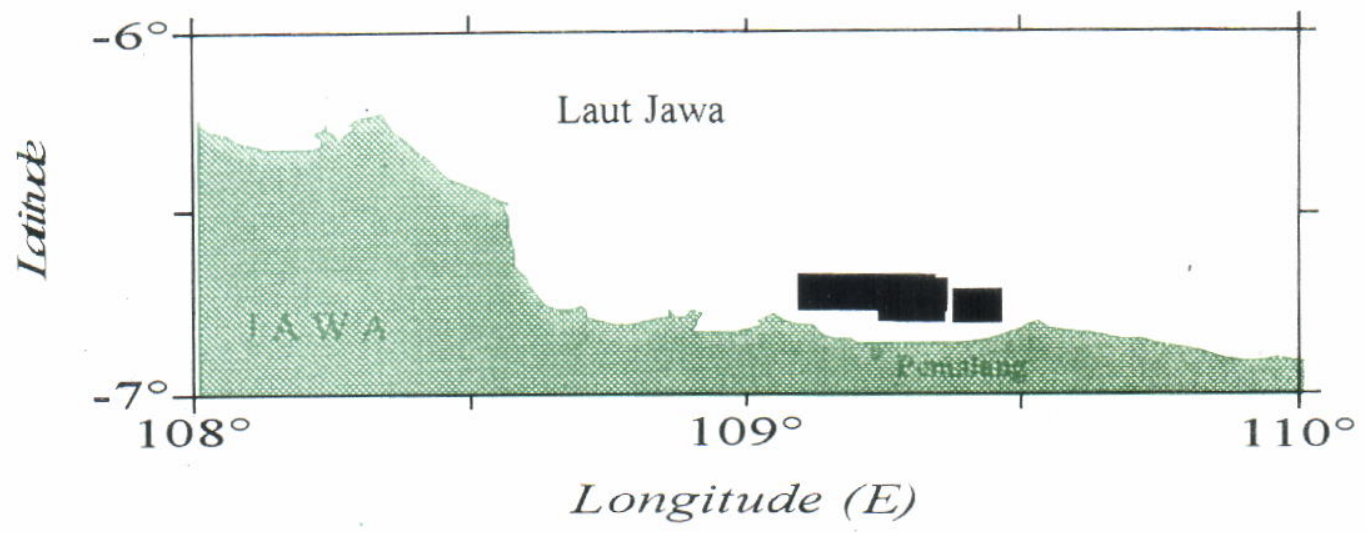

Gambar 1. Daerah penangkapan purse seine mini. 
Kapal jaring terbuat dari kayu dengan ukuran panjang $12 \mathrm{~m}$, lebar $3,5 \mathrm{~m}$, dan dalam $1,2 \mathrm{~m}$, bermesin diesel $24 \mathrm{HP}$ dengan jumlah $\mathrm{ABK}$ antara 17 sampai dengan 20 orang. Kapal lampu terbuat dari kayu dengan panjang $10 \mathrm{~m}$, lebar 2,25 m, dan dalam $1 \mathrm{~m}$, menggunakan 2 lampu galaksi (@ 400 watt) dan antara 5 sampai dengan 6 lampu mercury (@ 400 watt), bermesin diesel 24 HP dengan jumlah $A B K 3$ orang.

\section{Deskripsi Alat}

Purse seine mini di perairan Pemalang terdiri atas 2 bagian utama yaitu sayap dan kantong. Bagian kantong terletak di tengah yang diapit oleh bagian sayap pada ke-2 sisi dengan ukuran yang sama besar. Panjang jaring $280 \mathrm{~m}$ dan dalam 23 $\mathrm{m}$, dengan menggunakan perhitungan massa jaring diperoleh keseluruhan bobot jaring 144,21 $\mathrm{kg}$.

Panjang tali pelampung yang digunakan $280 \mathrm{~m}$ terbuat dari bahan PE dengan diameter $6 \mathrm{~mm}$ dan tali pemberat $300 \mathrm{~m}$ terbuat dari bahan PE berdiameter $10 \mathrm{~mm}$. Pelampung yang digunakan tipe $\mathrm{Y}-50$ dan A-8 dengan jarak antar pelampung 20 sampai dengan $25 \mathrm{~cm}$. Pemberat menggunakan timah dengan bobot rata-rata $125 \mathrm{~g}$ dengan jarak $20 \mathrm{~cm}$. Cincin terbuat dari bahan kuningan berdiameter $15 \mathrm{~cm}$ yang berjarak 3 sampai dengan $4 \mathrm{~m}$. Panjang tali kolor $350 \mathrm{~m}$ terbuat dari bahan PE dengan diameter $25 \mathrm{~mm}$. Desain ukuran keseluruhan alat tangkap dapat dilihat pada (Gambar 2).

Hangging ratio adalah panjang jaring yang terpasang. Semakin besar bukaan mata jarring, maka akan semakin kecil resistensi di dalam air. Nilai hangging ratio pukat cincin yang digunakan nelayan di Pemalang dihitung dengan menggunakan perhitungan (3) adalah 0,34 untuk seluruh bagian. Dengan nilai tersebut diharapkan mampu meningkatkan kecepatan tenggelam jaring saat dioperasikan.

\section{Daya Apung dan Tenggelam}

Daya apung ditimbulkan oleh tali-temali dan pelampung, sedangkan daya tenggelam ditimbulkan oleh pemberat timah, cincin, dan bahan jaring itu sendiri. Dengan menggunakan rumus perhitungan (2) diperoleh nilai daya apung dan tenggelam mini purse seine yang dapat dilihat pada Tabel 1.

Dari Tabel tersebut terlihat bahwa perbandingan antara daya apung dan tenggelam adalah sekitar 2 atau daya apung adalah 2 kali daya tenggelam.

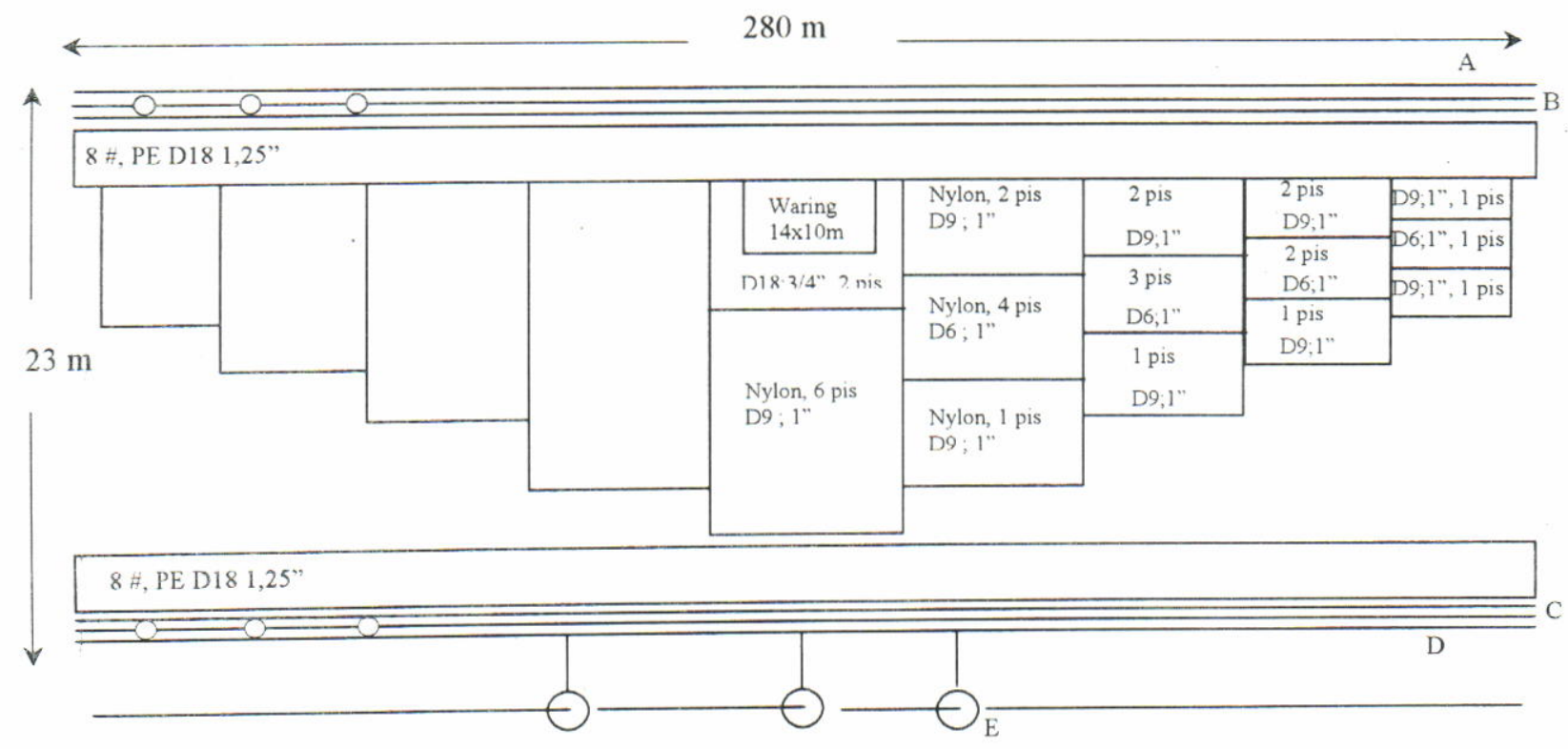

Gambar 2. Deskripsi ukuran mini purse seine di Pemalang.

\footnotetext{
Keterangan/Remarks:

A. Tali ris atas $P E \varnothing 6 \mathrm{~mm}$

B. Tali pelampung $280 \mathrm{~m}$, PE $\varnothing 6 \mathrm{~mm}$, Pelampung Y-50 (brown) dan A-8 (white). Jarak antar pelampung 20 sampai dengan $25 \mathrm{~cm}$

C. Tali ris bawah PE $\varnothing 6 \mathrm{~mm}$

D. Tali pemberat $280 \mathrm{~m}, \mathrm{PE} \varnothing 10 \mathrm{~mm}$, Pemberat timah $(@=125 \mathrm{~g})$. Jarak antar pemberat $20 \mathrm{~cm}$

E. Cincin kuningan $\varnothing 15 \mathrm{~cm}$, Tali kolor $350 \mathrm{~m}, \mathrm{PE} \varnothing 25 \mathrm{~mm}$

F. Jarak antar cincin 3 sampai dengan $4 \mathrm{~m}$
} 
Tabel 1. Daya apung dan daya tenggelam material mini purse seine di Pemalang

\begin{tabular}{|c|c|c|c|c|}
\hline No. & Material & Jumlah & $\begin{array}{l}\text { Bouyancy } \\
(\mathrm{Kg})\end{array}$ & $\begin{array}{l}\text { Singking force } \\
(\mathrm{Kg})\end{array}$ \\
\hline 1 & Webbing & 54 pis & - & 24,9 \\
\hline 2 & Buoy & $1.400 \mathrm{bh}$ & 700,00 & - \\
\hline 3 & Sinker & $1.800 \mathrm{bh}$ & - & 247,5 \\
\hline 4 & Ropes & $200 \mathrm{~kg}$ & 35,86 & - \\
\hline 5 & Ring & $90 \mathrm{bh}$ & - & 48,3 \\
\hline \multicolumn{3}{|c|}{ Total } & 735,86 & 320,7 \\
\hline
\end{tabular}

Perbandingan ini sesuai dengan nilai rasio daya apung dan daya tenggelam yang dikemukakan oleh Prado \& Dremiere (1991). Dalam praktek nilai daya apung pada pukat cincin sekitar 1,5 sampai dengan 2,5 kali dari jumlah pemberat yang dipasang.

\section{Operasional Penangkapan}

Purse seine di Pemalang pada umumnya dioperasikan dengan menggunakan 2 buah kapal yaitu kapal jaring dan kapal lampu. Ikan yang menjadi tujuan penangkapan adalah ikan-ikan yang membentuk kelompok di sekitar kapal lampu. Dengan demikian terlihat bahwa purse seine ini tidak dioperasikan untuk mengejar gerombolan ikan tetapi dengan memanfaatkan alat bantu penangkapan yaitu kapal lampu.
Operasi penangkapan dilakukan pada malam hari atau sebelum fajar dengan frekuensi penawuran 1 kali pada tiap jenis kapal lampu. Tawur dilakukan dengan cara kapal jaring melingkarkan jaring pada daerah sasaran setelah mendapat tanda dari kapal lampu dengan tetap memperhatikan kondisi angin dan arus. Penarikan tali kolor dilakukan secepat mungkin setelah pelingkaran selesai. Lolos gerombolan ikan dari jaring sangat dipengaruhi oleh kecepatan penarikan tali kolor (purse line).

\section{Komposisi Tangkapan}

Ikan hasil tangkapan (27 kali tawur) yang didaratkan $3393,5 \mathrm{~kg}$ dengan laju tangkap (catch rate) $125 \mathrm{~kg}$ per tawur. Hasil tangkapan terdiri atas

Tabel 2. Jumlah dan persentase hasil tangkapan mini purse seine di perairan Pemalang dalam 27 kali tawur, bulan September sampai dengan Oktober 2004

\begin{tabular}{|c|c|c|c|c|c|c|c|c|c|c|c|c|}
\hline \multirow[b]{2}{*}{ No. } & \multirow{2}{*}{$\begin{array}{l}\text { Catch } \\
\text { (kg) }\end{array}$} & \multicolumn{11}{|c|}{ Persentase hasil tangkapan ( $\%$ ) } \\
\hline & & Tembang & Layur & cumi & Tongkot: & Bawal & Kembung & sefar & Tengkek & Tert & Bentong & $\begin{array}{l}\text { Lain } \\
\text { lain }\end{array}$ \\
\hline 1 & 182 & 82,4 & & & & & 6,6 & 2,2 & 3,3 & 5,5 & & \\
\hline 2 & 54 & 46,3 & & & & & 5,6 & 37,0 & 5,6 & 5,6 & & \\
\hline 3 & 105,5 & 71,1 & & 5,7 & & & 5,7 & & 11,8 & tis & 5,7 & \\
\hline 4 & 75 & 100,0 & & & & & & & & & & \\
\hline 5 & 50 & 50,0 & & 38,0 & & & 12,0 & & & & & \\
\hline 6 & 80 & 31,2 & & 47,5 & & 21,2 & & & & . & & \\
\hline 7 & 77 & 13,0 & 51,9 & 20,8 & & 9,1 & & & & & & 5,2 \\
\hline 8 & 9 & 22,2 & & 33,3 & & & & 22,2 & & & & 22,2 \\
\hline 9 & 68 & 36,8 & 54,4 & 8,9 & & & & & & & & \\
\hline 10 & 227 & 66,1 & & & & 14,1 & & & 8,8 & 11,0 & & \\
\hline 11 & 59,5 & 42,0 & & & & 21,8 & 16,8 & & 19,3 & & & \\
\hline 12 & 119,5 & 31,4 & & 15,1 & & & 10,5 & 20,9 & 16,7 & & 5,4 & \\
\hline 13 & 23 & & & 100,0 & & & & & & & & \\
\hline 14 & 55 & 45,4 & & 29,1 & & 25,4 & & & & & & \\
\hline 15 & 176 & & 45,4 & 25,0 & 25,6 & 40 & & & & & & \\
\hline 16 & 562 & 93,4 & & & 4,4 & & 1,2 & & & & & 0,9 \\
\hline 17 & 85 & 88,2 & & & & & 11,8 & & & & & \\
\hline 18 & 23 & & & 69,6 & & & & & & & 30,4 & \\
\hline 19 & 100 & 100,0 & & & & & & & & & & \\
\hline 20 & 57 & & 43,9 & 35,1 & & 10,5 & & & & & 10,5 & \\
\hline 21 & 56 & & 44,6 & 48,2 & & & & 7,1 & & & & \\
\hline 22 & 48 & & 52,1 & 47,9 & & & & & & & & \\
\hline 23 & 117 & & 64,1 & 8,5 & & 60 & & 21,4 & & & & \\
\hline 24 & 158 & 47,5 & 47,5 & 5,1 & & & & & & & & \\
\hline 25 & 96 & & & & 100,0 & & & & & & & \\
\hline 26 & 93 & & & 6,4 & 66,7 & & 26,88 & & & & & \\
\hline 27 & 638 & 98,0 & & & & & & & & & & 2.1 \\
\hline
\end{tabular}


ikan tembang (Sardinella fimbriata) 60,68\% (2059,5 $\mathrm{kg}$ ), layur (Trichiurus savala) 11,25\% (382 kg), cumi (Loligo indica) 8,81\% (299 kg), tongkol (Auxis thazard) $6,71 \%(228 \mathrm{~kg}$ ), bawal hitam (Formio niger) $3,03 \% \quad(103 \mathrm{~kg})$, kembung perempuan (Restrelliger negletus) 2,69\% (91,5 kg), selar kuning (Selaroides leptolepis) 2,35\% (80 kg), tetengkek (Megalaspis cordyla) 2,15\% (73 kg), teri (Stelephorus spp.) 1,19\% (38 kg), selar bentong (Selar crumenophtalmus) $0,75 \%(25,5 \mathrm{~kg})$, panyul
(Mene maculata) $0,41 \%(14 \mathrm{~kg})$, dan tenggiri (Scomberomorus spp.) 0,29\% (10 kg) (Tabel 2).

Pengambilan contoh biologi dilakukan terhadap tetengkek (Megalaspis cordyla) 36 ekor, kembung (Restreliger brachyoma) 177 ekor. tembang (Sardinella fimbriata) 79 ekor, bentong (Selaroides boops) 30 ekor, selar kuning (Selaroides leptolepis) 144 ekor, dan bawal hitam (Formio niger) 48 ekor. Hasil pengukuran pada Tabel 3 dan Gambar 3.

Tabel 3. Kisaran panjang cagak (FL) dan bobot ikan dominan tertangkap

\begin{tabular}{|c|c|c|c|c|c|}
\hline No: & denis & $\begin{array}{l}\text { Kisaran } \\
\text { Ct (cm) }\end{array}$ & Rata raca & ktsaran bobot (g) & $\begin{array}{l}\text { Ratar ata } \\
\text { Bobot (g) }\end{array}$ \\
\hline 1 & Kembung & $8-14$ & 10,68 & $10-25$ & 15 \\
\hline 2 & Tetengkek & $16-26$ & 20,44 & $10-20$ & 14 \\
\hline 3 & Tembang & $9-11$ & 9,62 & $13-17$ & 15 \\
\hline 4 & Bentong & $17-24$ & 19,87 & $14-40$ & 19 \\
\hline 5 & Selar & $10-20$ & 12,42 & $10-45$ & 29 \\
\hline 6 & Bawal & $18-28$ & 21,17 & $165-670$ & 325 \\
\hline
\end{tabular}

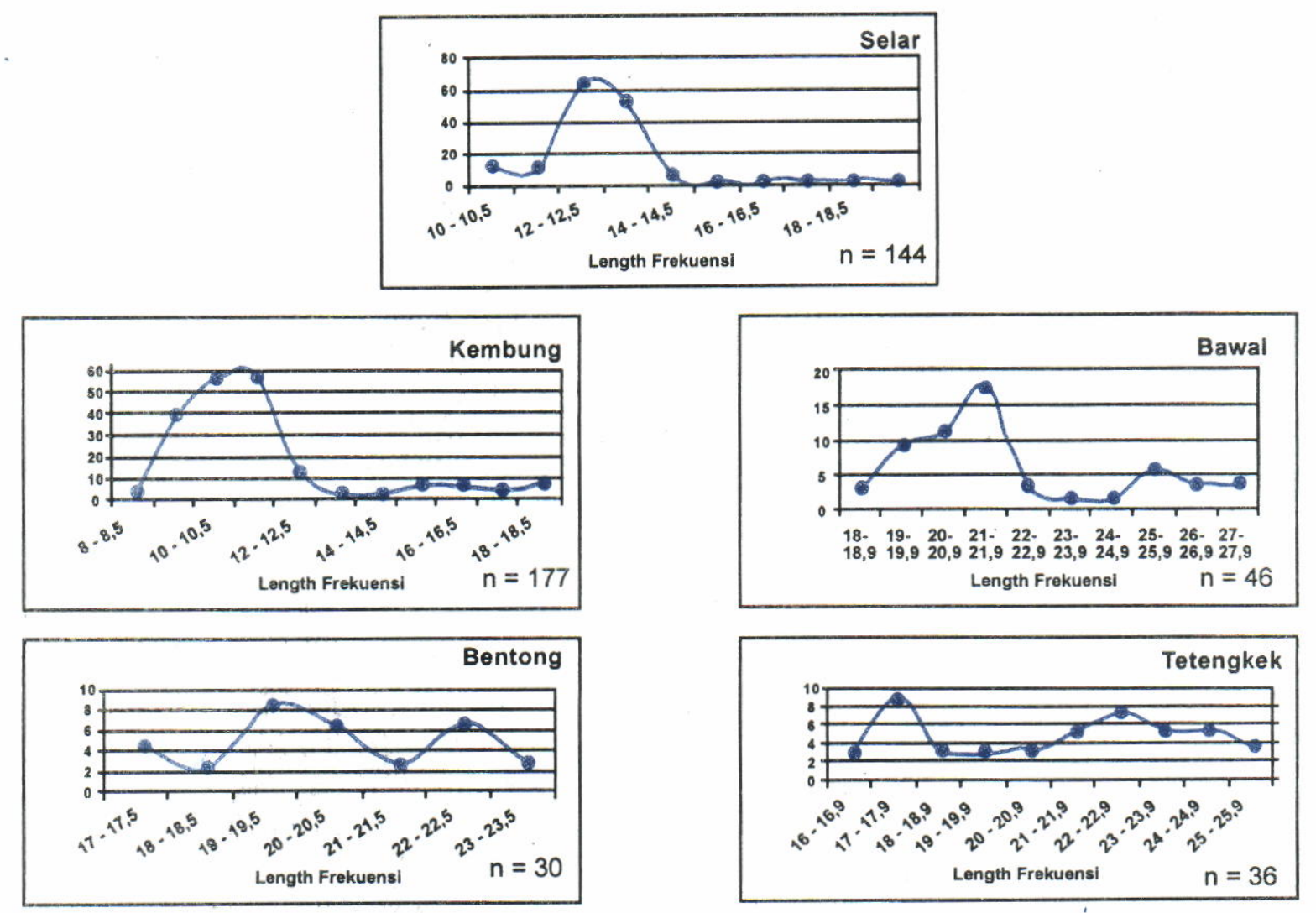

Gambar 3. Grafik panjang cagak ikan dominan yang tertangkap dengan mini purse seine di Pemalang, bulan September sampai dengan Oktober 2004. 


\section{KESIMPULAN}

1. Total hasil tangkapan mini purse seine dari 27 kali tawur di perairan Pemalang $(3393,5 \mathrm{~kg})$ didominasi oleh jenis ikan tembang (Sardinella fimbriata) yaitu $60,7 \%$ dari total hasil tangkapan, diikuti oleh layur $(11,3 \%)$, cumicumi $(8,8 \%)$, tongkol $(6,7 \%)$, dan ikan lain kurang dari $5 \%$.

2. Laju tangkap mini purse seine yang diperoleh $125,7 \mathrm{~kg}$ per tawur.

3. Karakteristik mini purse seine di Pemalang efektif untuk penangkapan ikan.

4. Perikanan mini purse seine di Pemalang menggunakan teknologi cahaya sebagai alat bantu penangkapan.

\section{DAFTAR PUSTAKA}

Merta, G. S. \& H. M. Eidman. 1995. Prediction of biomass, yield and value of the lamuru (Sardinella lemuru) fishery in the Bali Strait. Biodynex. Pelfis Project CRIFI. p 137-144.

Nurhakim, S., B. Sadhotomo, \& M. Potier. 1995. Composite model on small pelagic resources. Biodynex. Pelfis Project CRIFI. p 145-153.
Potier, M. \& B. Sadhotomo. 1995. Exploration of the large and medium seiners fisheries. Biodynex. Pelfis Project CRIFI. p 195-214.

Prado, J. \& P. Y. Dremiere. 1991. Fishermen work book. FAO Rome. Italy. 174 p.

Sadhotomo, B. \& M. Potier. 1995. Exploratory scheme for the recruitmentand migration of the main pelagic species. Biodynex. Pelfis Project CRIFI. p 155-168.

Sainsbury, J. C. 1971. Commercials fishing method. Fishing News Ltd. London-119p.

Wijopriono. 1993. Observation on several fishing aspect of big purse seiner in the Java Sea. Workshop on Vessel, Gear, Post Harvest, Technologies and Socio Economic, ot the Java Sea Purse Seiner Fishery. Semarang 13-14 October 1993.

Wijopriono, J. Durant, \& P. Gueguen. 1995 Seiners vessel. Current Status and Potensial Innovation. Seminar on Socio Economic, Innovation, and Management of the Small Pelagic Fishery of the Java Sea, Bandungan Semarang. 4-7 December 1995. 